\title{
Plan for PLEX X-Ray Ablation Experiments and Analysis
}

\author{
J. Latkowski, S. Reyes
}

September 27, 2001

U.S. Department of Energy

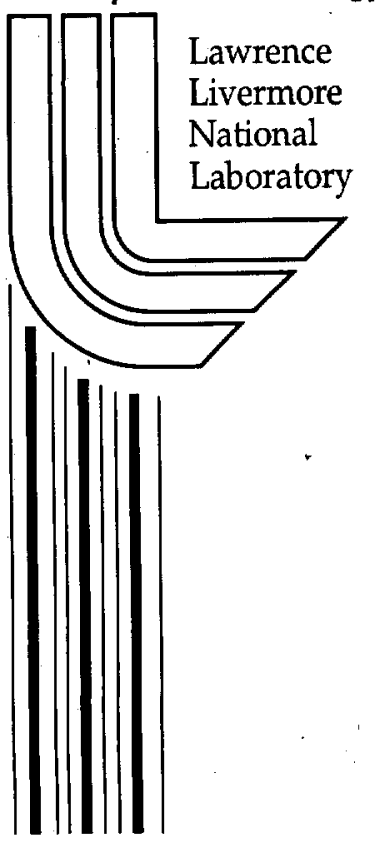




\section{DISCLAIMER}

This document was prepared as an account of work sponsored by an agency of the United States Government. Neither the United States Government nor the University of California nor any of their employees, makes any warranty, express or implied, or assumes any legal liability or responsibility for the accuracy, completeness, or usefulness of any information, apparatus, product, or process disclosed, or represents that its use would not infringe privately owned rights. Reference herein to any specific commercial product, process, or service by trade name, trademark, manufacturer, or otherwise, does not necessarily constitute or imply its endorsement, recommendation, or favoring by the United States Government or the University of California. The views and opinions of authors expressed herein do not necessarily state or reflect those of the United States Government or the University of California, and shall not be used for advertising or product endorsement purposes.

This work was performed under the auspices of the U.S. Department of Energy by the University of California, Lawrence Livermore National Laboratory under Contract No. W-7405-Eng-48.

This report has been reproduced directly from the best available copy.

Available electronically at http://www.doe.gov/bridge

Available for a processing fee to U.S. Department of Energy and its contractors in paper from

U.S. Department of Energy

Office of Scientific and Technical Information

P.O. Box 62

Oak Ridge, TN 37831-0062

Telephone: (865) 576-8401

Facsimile: (865) 576-5728

E-mail: reports@adonis.osti.gov

Available for the sale to the public from

U.S. Department of Commerce

National Technical Information Service

5285 Port Royal Road

Springfield, VA 22161

Telephone: (800) 553-6847

Facsimile: (703) 605-6900

E-mail: orders@ntis.fedworld.gov

Online ordering: http://www.ntis.gov/ordering.htm

OR

Lawrence Livermore National Laboratory

Technical Information Department's Digital Library

http://www.llnl.gov/tid/Library.html 


\section{Plan for PLEX X-Ray Ablation Experiments and Analysis}

\section{Table of Contents}

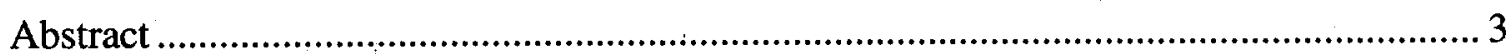

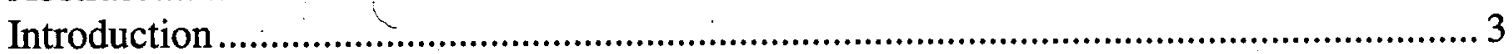

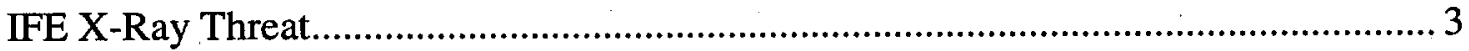

Power Plant Requirements ............................................................................ 3

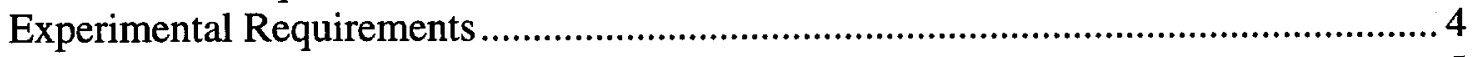

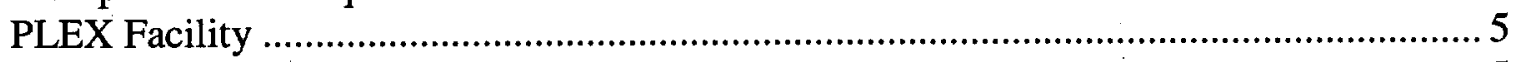

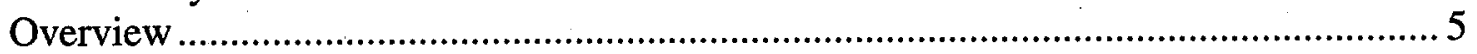

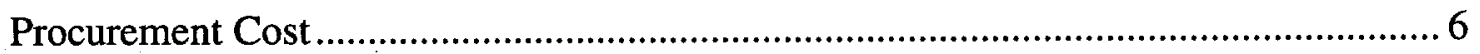

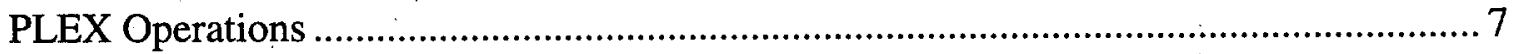

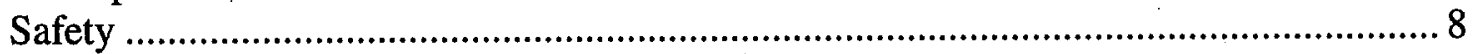

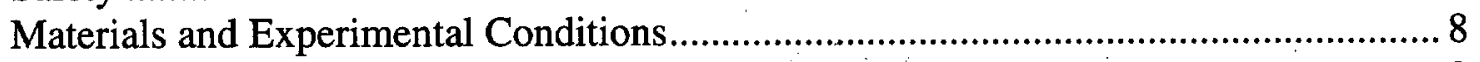

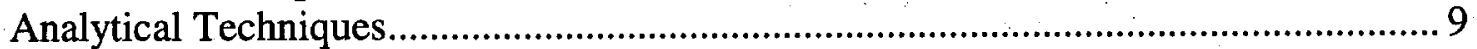

Computational Analysis ................................................................................. 10

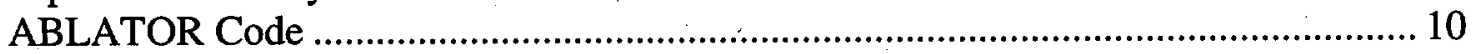

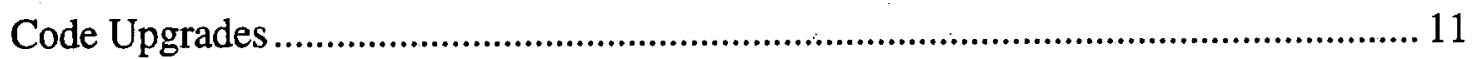

Potential Collaborations ................................................................................... 12

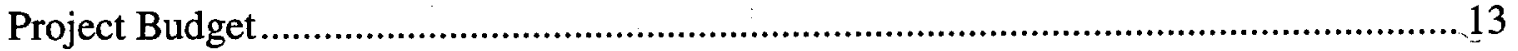

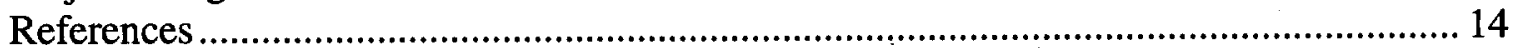




\section{Plan for PLEX X-Ray Ablation Experiments and Analysis}

\section{Abstract}

PLEX is a Z-pinch based $\mathrm{x}$-ray source that can produce $\mathrm{x}$-rays with fluences (0.3-18 $\left.\mathrm{J} / \mathrm{cm}^{2}\right)$, pulselengths $(10-30 \mathrm{~ns})$, repetition rates $(<10 \mathrm{~Hz})$, and energies $(50-500 \mathrm{eV})$ of interest for IFE chambers and optics. It provides an affordable, dedicated method to advance our understanding of $\mathrm{x}$-ray damage to materials. The PLEX $\mathrm{x}$-ray source will be used to experimentally validate and further develop the ABLATOR $x$-ray ablation code for use in inertial fusion energy (IFE) studies.

\section{Introduction}

Materials in an IFE power plant will be exposed to significant per-shot fluences of $x$ rays. These $x$-rays can lead to uniform or non-uniform removal of material from the chamber wall or final optic via a process called $x$-ray ablation. Both the chamber wall and the final optics have demanding requirements with respect to tolerable levels of ablation. To ensure that the chamber wall and final optics in an actual IFE power plant would survive, it is essential that $\mathrm{X}$-ray ablation experiments and computational modeling are performed for a relevant set of conditions. These conditions are introduced in this section of the plan.

It is worth noting that it is not only IFE power plants that would be subject to significant X-ray fluences; research and development (R\&D) facilities such as the Integrated Research Experiment and the Engineering Test Facility will also need to be concerned about X-ray ablation [1].

\section{IFE X-Ray Threat}

The targets used in IFE power plants will emit a small fraction of their output in the form of x-rays. For the Naval Research Laboratory (NRL) radiation pre-heated directdrive target [2], approximately $1.4 \%$ of the output is in X-rays with a spectrum that has a broad peak from $\sim 0.5$ to $30 \mathrm{keV}$ and a pulselength of $\sim 10 \mathrm{~ns}$ [3]. Significant portions of the $\mathrm{x}$-ray spectrum extend from $\sim 20 \mathrm{eV}$ to $100 \mathrm{keV}$. Figure 1 shows the $\mathrm{x}$-ray spectrum emitted by the NRL target, in addition to that from an indirect-drive target. For a $400 \mathrm{MJ}$ yield used in conjunction with the typical chamber and final optic parameters, this results in $\sim 1 \mathrm{~J} / \mathrm{cm}^{2}$ of $\mathrm{x}$-rays at the chamber wall and $\sim 50 \mathrm{~mJ} / \mathrm{cm}^{2}$ at the optic. These $\mathrm{x}$-rays present a significant threat.

\section{Power Plant Requirements}

The $\mathrm{x}$-ray ablation requirements are quite stringent for both the chamber wall and final optics systems. For a solid chamber wall, the ablation of even 1 angstrom per shot is not acceptable. Given a repetition rate of $\sim 5 \mathrm{~Hz}$, this would result in the ablation of 1.6 $\mathrm{cm}$ per year. This exceeds the thickness of the chamber wall in most designs. As a rough estimate, the chamber wall ablation should be limited to approximately $1 \mathrm{~mm}$ after $10^{8}$ shots. This corresponds to 0.01-0.1 monolayers of material removed per shot.

For the final optics, the requirements may be even more challenging. The nonuniform removal of material from the final optics at the $\lambda / 10$ level would affect the 


\section{Plan for PLEX X-Ray Ablation Experiments and Analysis}

ability to focus laser light [1]. For either a $\mathrm{KrF}$ or diode-pumped solid-state laser, this corresponds to the non-uniform removal of a layer of only $25-35 \mathrm{~nm}$. With an optics lifetime of $\sim 1$ year, this results in a non-uniform removal limit of $\sim 10^{-5}$ monolayers per shot.

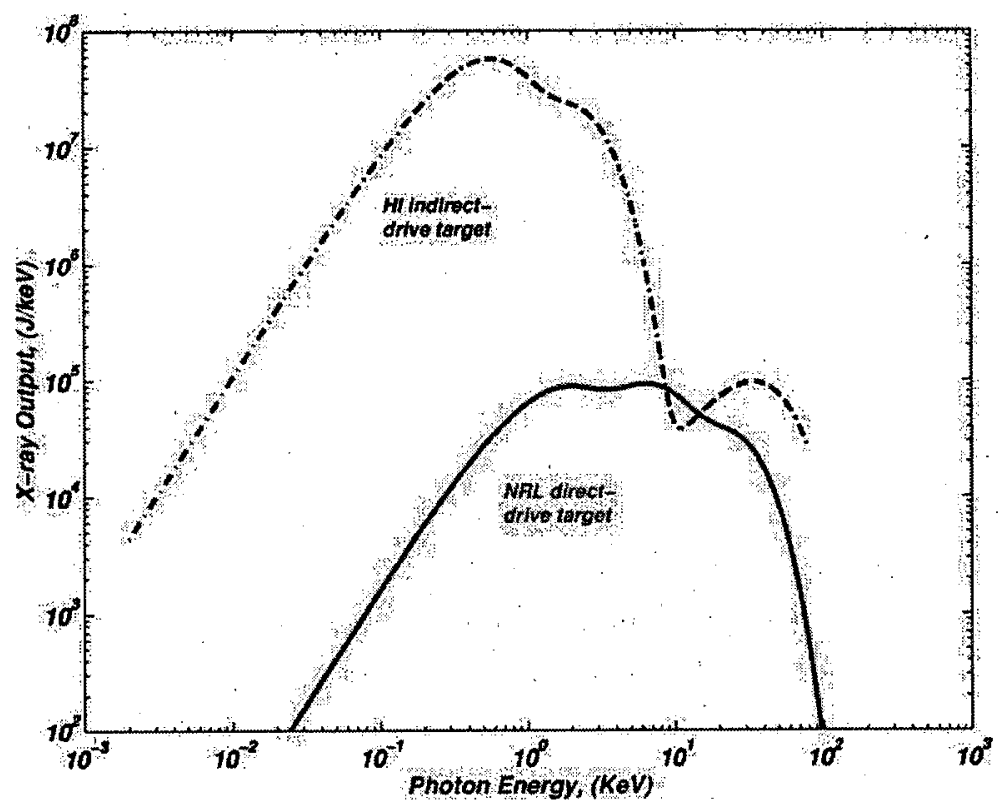

Figure 1. The $x$-ray spectrum emitted from the NRL direct-drive target is $\sim 10 \times$ harder than that from an indirect-drive target. Note that the NRL target yield of $154 \mathrm{MJ}$ is $\sim 3 \times$ lower than that from the indirect-drive target (458 MJ).

\section{Experimental Requirements}

Previous work has studied x-ray ablation for slightly, but significantly, different conditions. Anderson examined x-ray ablation for the development of the first wall and beamdumps of the National Ignition Facility (NIF) [4,5]. For NIF design activities, single- and several-shot exposures were of the greatest interest due to their utility in predicting the need for cleaning within the target chamber, replacement of the final optics (ablated chamber material would condense on optical surfaces), and damage to diagnostics and other in-chamber instruments. The NIF x-ray spectrum will be "softer" than that from a high-yield, direct-drive target; even ignition targets have blackbody temperatures of only a few hundred eV. Finally, the NIF chamber and optics are to be under vacuum conditions.

Anderson's results demonstrated significant (1-100 $\mathrm{nm}$ ) ablation layer thicknesses at $\mathrm{x}$-ray fluences of $\sim 1 \mathrm{~J} / \mathrm{cm}^{2}$ in fused silica, aluminum, silicon carbide, and other materials. The removal of such thicknesses would be intolerable for either the chamber or final optics. IFE experiments on $x$-ray ablation must be able to achieve prototypical chamber wall fluences of $1 \mathrm{~J} / \mathrm{cm}^{2}$.

Although the x-ray fluences experienced by IFE final optics are expected to be below the single-shot ablation threshold (for a pristine material), it is unclear if there are other 


\section{Plan for PLEX X-Ray Ablation Experiments and Analysis}

mechanisms that would lead to multi-shot loss of material when exposed to sub-threshold fluences. Additionally, data is not available for materials that have been exposed to ion and/or neutron irradiation. IFE experiments on $x$-ray ablation must be able to explore sub-threshold regimes of exposure, which will require a large number of shots.

It has been proposed that one might be able to obtain the same information via a series of cheaper, laser ablation experiments. Due to fundamental differences in the processes, however, laser ablation experiments are unlikely to provide the ultimate answer. The largest distinction between x-ray and laser ablation is the depth of energy deposition within the material [4]. X-rays with energies of several hundred electron volts typically deposit their energy over microns of material, while laser light would be absorbed within only nanometers due to the low photon energies $(\sim \mathrm{eV})$.

Due to the difference in photon energies and deposition depths, laser ablation is entirely a surface phenomenon. X-ray ablation (without vaporization), however, can be modeled with the front surface as a thermally insulated boundary. As the interior material is heated, a substantial layer of two-phase material can be created [4]. In x-ray ablation, the longer deposition depths also emphasize the effects of hydrodynamic motion; rapid heating of the internal material produces high pressures, which can drive expansion of the surface layers away from the bulk of the material [4]. Once the expansion stops, rarefaction waves propagate into the bulk of the material. Such effects can be very important as mechanisms for ablation of heated material [4]. Additionally, x-rays are of sufficient energy so as to break chemical bonds. Laser photon energies, at only several $\mathrm{eV}$, are insufficient to break chemical bonds. IFE experiments on ablation should use an $x$-ray source to correctly simulate conditions that would be experienced by the chamber wall and optics.

\section{PLEX Facility}

The PLEX facility is manufactured by PLEX LLC, which is located in Brookline, Massachusetts. The information contained in the following section is based upon a fax sent to John Sethian and Steve Payne by the company founder, Malcolm McGeoch. Additional information, including figures, has been obtained from the PLEX LLC website: www.xuv.com.

\section{Overview}

PLEX is a Z-pinch based radiation source that delivers $50-500 \mathrm{eV} \mathrm{X}$-rays at a repetition frequency of up to $10 \mathrm{~Hz}$. Many details of PLEX are given in reference 6 . The device, shown in Figure 2, uses a radio-frequency $(1 \mathrm{GHz})$ pulse to pre-ionize a lowpressure ( $\sim 0.2$ Torr) gas fill, generating a plasma density of $10^{13}-10^{14} \mathrm{e}^{-/ \mathrm{cm}^{3}}$. The $\mathrm{rf}$ pulse is followed by a current of $150 \mathrm{kA}$, which causes the Z-pinch. The X-ray emission peaks $\sim 250 \mathrm{~ns}$ later, which is approximately $40 \mathrm{~ns}$ after the time of maximum density and temperature.

When used with xenon gas, the X-ray spectrum peaks at $113 \mathrm{eV}$ (11 nm wavelength). PLEX is capable of delivering, via an ellipsoidal collector, a fluence of $18 \mathrm{~J} / \mathrm{cm}^{2}$ with a $3.0 \mathrm{~mm}$ diameter spot size. When used with nitrogen, the $430 \mathrm{eV}(2.9 \mathrm{~nm})$ nitrogen VI 


\section{Plan for PLEX X-Ray Ablation Experiments and Analysis}

resonance is emphasized. A fluence of $0.27 \mathrm{~J} / \mathrm{cm}^{2}$ is delivered with a $1.4 \mathrm{~mm}$ spot size. At the $430 \mathrm{eV}$, the $\mathrm{x}$-ray pulse length was measured at $12 \pm 5 \mathrm{~ns}$. The pulse length at $113 \mathrm{eV}$ was not measured, but is expected to be $<30$ ns.
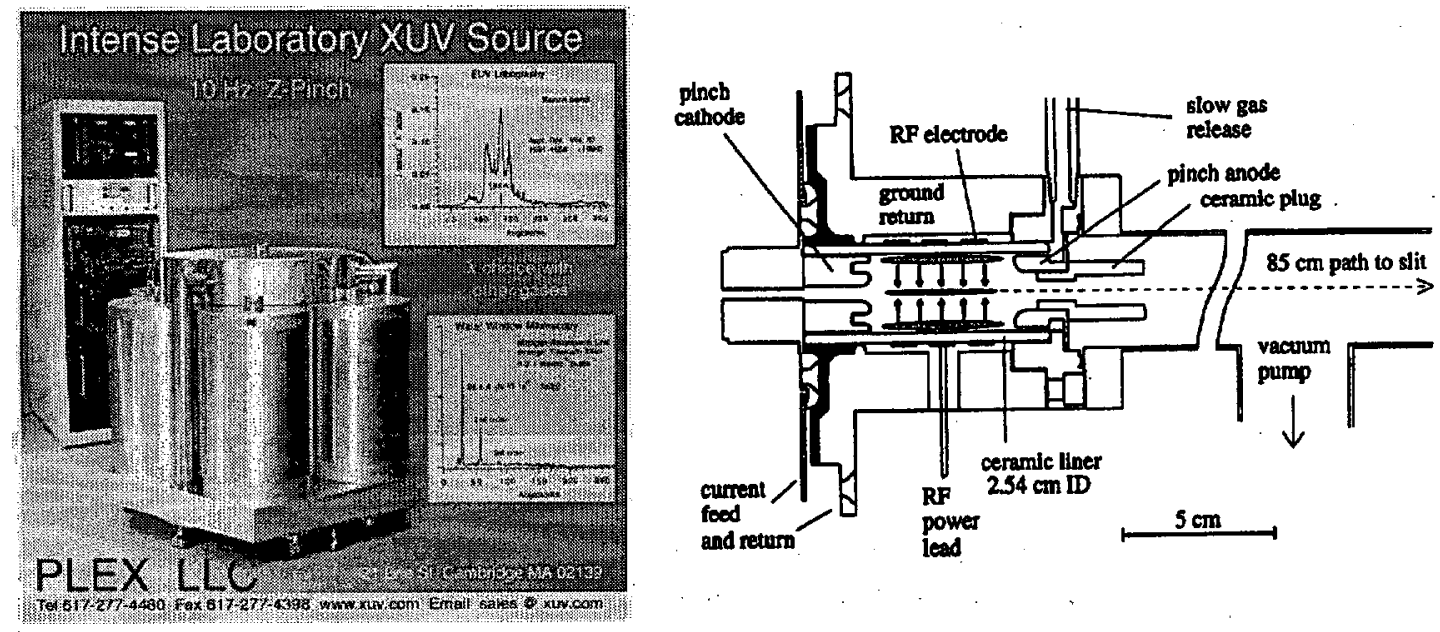

Figure 2. The PLEX facility, which uses an rf-initiated Z-pinch to produce X-rays, fits on a table-top.

By using a variety of gases, one can generate $x$-rays at wavelengths from $20-225 \mathrm{~nm}$ $(\sim 50-500 \mathrm{eV}) . \mathrm{X}$-ray spectra generated using three different gases are shown in Figure 3. Through the use of filters, one can generate nearly pure line energies.
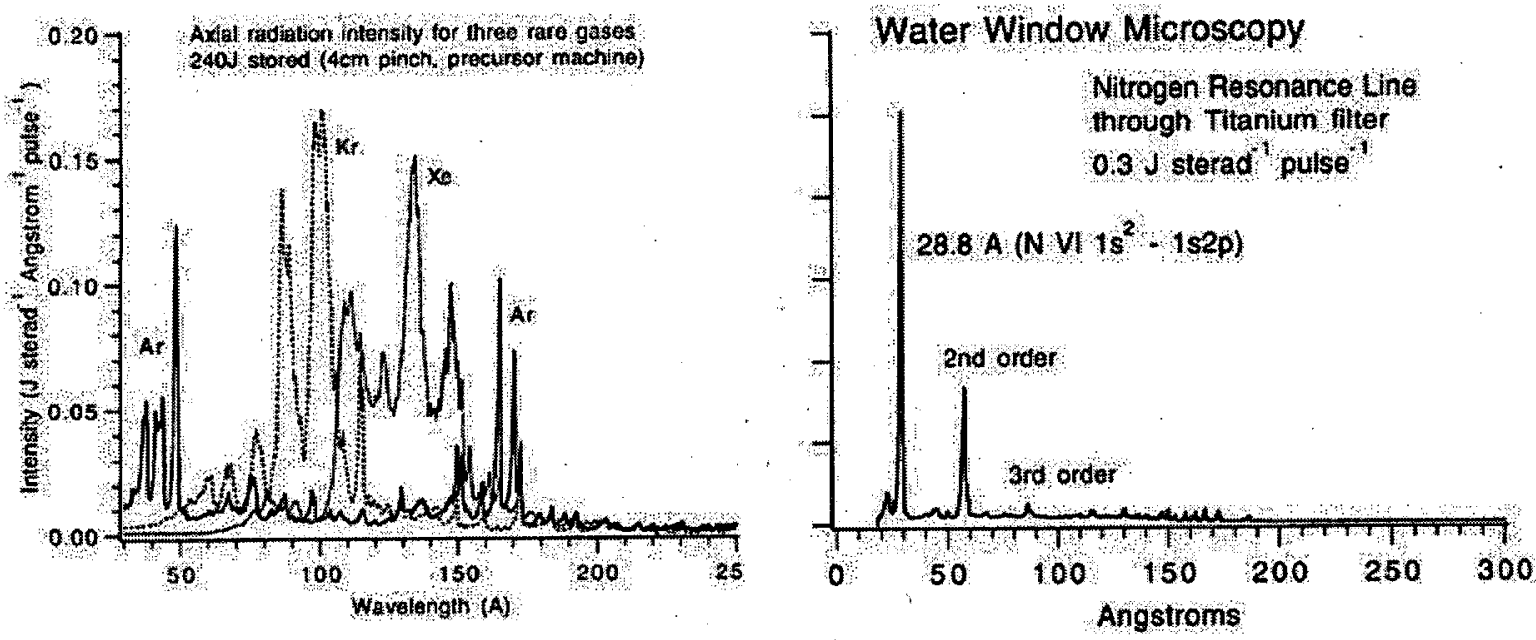

Figure 3. With different gases, PLEX can generate a variety of $\mathrm{x}$-ray energies.

\section{Procurement Cost}

A quote for the purchase of the PLEX facility was provided by Malcolm McGeoch on April 25, 2001. This quote was for a re-assembled machine that would be equipped with larger capacitors. New vacuum pumps would be included, and additional interlocks would be provided. Included in the quote is an allocation for shipping and installation. The total facility cost is $\$ 320 \mathrm{~K}$. Table 1 gives a breakdown of this cost. The quote states 


\section{Plan for PLEX X-Ray Ablation Experiments and Analysis}

that delivery would require approximately $4-5$ months with the limiting item being the manufacture/delivery of the ellipsoidal collectors.

Table 1. Cost breakdown for PLEX procurement.

\begin{tabular}{lr}
\hline Item & Cost (K\$) \\
\hline $\begin{array}{l}\text { Basic machine } \\
\text { (modulators, frame and } \\
\text { power supply) }\end{array}$ & 200 \\
\hline Vacuum pumps & 16 \\
\hline $\begin{array}{l}\text { Re-designed pinch } \\
\text { components }\end{array}$ & 6 \\
\hline Filtered diodes & 4 \\
\hline Irradiation vacuum tank & 8 \\
\hline Ellipsoidal collectors (2) & 44 \\
\hline $\begin{array}{l}\text { Re-assembly, test and } \\
\text { integration }\end{array}$ & 30 \\
\hline Shipment and installation & 12 \\
\hline LLNL procurement taxes & 42 \\
\hline Total & 362 \\
\hline
\end{tabular}

It is worth noting that the quote from PLEX LLC includes two ellipsoidal collectors, which would enable operation at two wavelengths. If additional wavelengths are desired, then an additional expense would be incurred.

Not included in the quote, but necessary for basic facility installation, is a chiller or alternate cold water source. The total heat removal is $6 \mathrm{~kW}$ at $21^{\circ} \mathrm{C}$. A quote from one vendor, Lytron, came in at $\$ 6 \mathrm{~K}$ for a $7 \mathrm{~kW}, 6 \mathrm{gpm}$ unit that would be suitable for this application. With LLNL procurement taxes, the total cost of the chiller will be $\sim \$ 7 \mathrm{~K}$.

- Vacuum calorimeter needed for spectrometer absolute calibration?

- CCD camera provided with spectrometer?

- Other spectrometer equipment needed?

\section{PLEX Operations}

In using the PLEX facility, we expect to emphasize its unique capabilities. Specifically, PLEX will allow careful control of variables of importance to the X-ray irradiation and it is a rep-rated machine. Early experiments on PLEX will be focused on characterization of the facility. The $x$-ray spectrum will be characterized for xenon and nitrogen plasmas. Characterization will include measurement of the $\mathrm{x}$-ray spectrum, $\mathrm{x}$-ray pulse length, and shot-to-shot variation in beam energy and location. When the facility is transitioned from one gas to the other, characterization will be repeated prior to irradiation of samples.

It is envisioned that PLEX will be used in campaigns that will be conducted for each material. First, $\mathrm{x}$-ray exposures of a given material will begin with a single shot. Then, 


\section{Plan for PLEX X-Ray Ablation Experiments and Analysis}

irradiations will progress to several shots, 100 's of shots, and eventually, tens of thousands of shots. The ability to conduct more than 30,000 shots within one hour is a key strength of this facility. This will not only provide good statistics, it will enable the study of sub-threshold $\mathrm{x}$-ray damage mechanisms.

\section{Safety}

Radiological safety requirements for PLEX are expected to be minimal. Operation of PLEX will be authorized via an Integration Work Sheet, which is a standard LLNL form for description of activities to be performed and analysis of potential hazards and countermeasures. The vendor states that the exterior dose rate during PLEX operation is immeasurable. Based upon this information, LLNL Hazards Control, Team 2 has decided that PLEX will not even be classified as a radiation-generating device.

The primary hazard associated with PLEX operation will be electrical. Insert something here from the ES\&H folks after obtaining more information from Malcolm McGeoch and having a discussion with Gary Driefuerst.

\section{Materials and Experimental Conditions}

Materials of interest for IFE R\&D and power plants include a range of potential chamber wall and optical materials. Examples of chamber wall materials include carbonfiber composites, silicon carbide, and tungsten. Example optical materials include highpurity aluminum, fused silica, and certain liquid metals if used for a grazing incidence liquid metal mirror. R\&D facilities may utilize an even wider range of materials, especially for the chamber wall. Austenitic or ferritic steels, for example, are unlikely to be used in a dry wall power plant due to safety and environmental concerns. They might, however, be acceptable for use in development facilities. Therefore, such materials are also of interest.

Most of the design space for currently envisioned dry-wall IFE power plants calls for the use of low-pressure gases to attenuate $\mathrm{x}$-rays and charged particles that would be incident upon the chamber wall and final optics. The SOMBRERO power plant study called for a background gas pressure of 0.5 Torr Xe [7]. Recent work under the ARIES design group has reduced this gas pressure to $\sim 10 \mathrm{mTorr}$ to be consistent with target heating tolerances during injection [8]. One can envision the use of PLEX with a lowpressure fill gas to simulate such conditions (perhaps the gas could be kept out of the cathode area through use of a very thin membrane, which $\mathrm{x}$-rays could easily penetrate).

Other concepts call for the use of gas puffs or liquid Xe droplets for protection of the final optics [9]. PLEX could be modified to perform such experiments.

Work currently being conducted at the University of California at San Diego (UCSD) is centered on laser damage of optics. Included in this work is a study of the effects of contamination upon the laser damage threshold. Similarly, x-ray ablation may well be affected by the presence of contaminants. Studies of the x-ray ablation of materials contaminated with prototypical target debris could be conducted on PLEX. 


\section{Plan for PLEX X-Ray Ablation Experiments and Analysis}

It appears likely that ion and neutron irradiation of chamber wall and optical materials would alter their properties (e.g., thermal conductivity, tensile strength, etc.) sufficiently to affect $x$-ray ablation of such materials. Thus, the program should have the ability to conduct $\mathrm{x}$-ray ablation experiments upon materials that have previously been irradiated in other facilities. Such experiments are not the focus of the current plan for PLEX, but would appear possible, depending upon the levels of radioactivity involved, to perform $\mathrm{x}$ ray irradiation of such samples. The need for such exposures will be evaluated in the future. If deemed necessary, a plan for moving PLEX within a confinement system will be developed.

\section{Analytical Techniques}

Diagnosis of the $\mathrm{x}$-ray environment and determination of the effects upon samples exposed on PLEX will require several methods. Figure 3 shows detailed $x$-ray spectra obtained with several different fill gases. Although most of the energy is emitted at the first order wavelength, a non-negligible amount of energy is emitted at the higher, second and third order wavelengths. Longer wavelengths, lower energy photons deposit in a shorter depth, and thus, are potentially quite important for $\mathrm{x}$-ray ablation. Prior to exposure of samples, PLEX will be configured as shown in the schematic in Figure 2. In this configuration, an $x$-ray spectrometer is attached to the right, and the detailed $x$-ray spectra will be obtained. (Note: I am still working on access to an X-ray spectrometer such as MCPIGS. I'm being helped by Jeff Koch from the ICF Program at LLNL.)

The fundamental measurement of interest for this work is the ablation (or removal) depth resulting when a given material is exposed to a particular $\mathrm{x}$-ray fluence and spectrum. Material may be removed in small steps or it may be removed in a large quantity once the $\mathrm{x}$-ray damage has built up to a certain level. Experiments will be conducted for a varying number of pulses and fluences. Quantitative data on material removal depths will be obtained by measuring the surface height changes between exposed and masked regions. Atomic force microscopy (AFM), scanning electron microscopy (SEM), and optical microscopy will provide the basis for conclusions on material removal mechanisms.

Following exposure, samples will be analyzed using a profilometer, which uses a diamond-tipped stylus to scan a surface and provide information about surface topography. The tip scans across the surface of the sample, and an inductive sensor registers the vertical motion of the tip. The signal generated by the motion of the tip is used to create a two-dimensional profile of the surface. The Tencor Alpha-Step 200 Profilometer, several of which are available at LLNL, has a vertical resolution of 5 angstroms and a horizontal resolution of 400 angstroms.

AFM will be used to measure the three-dimensional surface topography on a scale from angstroms to hundreds of microns. Because its operation does not require a current between the sample surface and the tip, AFM can move into potential regions inaccessible to the scanning tunneling microscopy (STM) or image fragile samples which would be damaged irreparably by the STM tunneling current. Insulators, organic materials, biological macromolecules, polymers, ceramics and glasses are some of the 


\section{Plan for PLEX X-Ray Ablation Experiments and Analysis}

many materials which can be imaged in different environments, such as liquids, vacuum, and low temperatures.

AFM analysis will produce critical information about surface features with unprecedented clarity. AFM can examine any rigid surface, either in air or with the specimen immersed in a liquid. AFM can resolve very tiny features, including even single atoms. Yet, AFM offers a field of view of $125 \mu \mathrm{m}$ or more for determination of large-scale trends and investigation of features seen with other techniques such as visible light microscopy. AFM can also examine rough surfaces, since its vertical range is more than 5 microns. AFM will play an important role in the post-irradiation analysis of samples from PLEX. It will provide essential information on surface topography that should aid in the determination of mechanisms of material removal.

SEM will be another valuable tool for PLEX studies. Conducting samples or nonconducting samples coated with a conducting material are bombarded by an electron beam at energies of 0.5-30 keV. Secondary electrons are generated with an intensity governed by the surface topography of the sample. Spatial resolution on the order of 10 $\mathrm{nm}$ is possible, and SEM provides a large depth of field.

\section{Computational Analysis}

The PLEX facility cannot exactly replicate the $x$-ray spectrum that is expected from an IFE target. It can, however, replicate important parts of the IFE x-ray spectrum-the low energy photons that are stopped in a relatively thin layer of material. The ABLATOR code was developed to predict single-shot ablation by "soft" $\mathrm{x}$-rays $(\sim 200 \mathrm{eV})$ for short $(\sim 10 \mathrm{~ns})$ pulse lengths [4]. By demonstrating that ABLATOR can successfully predict $\mathrm{x}-$ ray ablation in the $50-500 \mathrm{eV}$ range, one gains confidence in its ability to predict $\mathrm{x}$-ray ablation for the broader IFE spectrum (100 eV-10 keV).

\section{ABLATOR Code}

ABLATOR is a one-dimensional Lagrangian finite difference code for the calculation of material response to $x$-rays. The code uses an explicit scheme in time, which provides for simple calculations, but it requires small time steps to guarantee numerical stability. ABLATOR was developed by Andrew Anderson of LLNL for application to the design of the first wall and laser beamdumps for the National Ignition Facility (NIF).

ABLATOR calculations were benchmarked, for a number of materials, using $x$-ray exposures on the Nova laser [4,5].

The transient ablation modeling for which ABLATOR is used has two goals: (1) to predict the amount of material removed by the X-rays, and (2) to determine the state of the ablated material after it leaves the surface. To accomplish its goals, ABLATOR models four different processes. These include the x-ray energy deposition, transient thermal conduction, thermal expansion (hydrodynamic motion), and material removal through surface vaporization and spall processes.

Because ABLATOR utilizes an explicit scheme in time, numerical stability limits typically force time steps to be on the order of a picosecond. A typical calculation spans 


\section{Plan for PLEX X-Ray Ablation Experiments and Analysis}

several hundred nanoseconds, so a large number of time steps are required. Still, a typical calculation requires only minutes on a $\mathrm{GHz}$-class $\mathrm{PC}$.

\section{Code Upgrades}

For use in the modeling of IFE x-ray ablation, modifications to the ABLATOR code will be needed. First, the $\mathrm{x}$-ray energy deposition model needs to be replaced. For its original application (an assessment of x-ray ablation on the NIF), ABLATOR's x-ray deposition model is adequate. For IFE conditions, however, an upgrade is required. The upgrade will enable ABLATOR to account for chamber fill gases (the NIF chamber is under hard vacuum conditions) and to accurately account for the effects of Compton scattering at higher energies.

For NIF applications, which are typically at lower photon energies (e.g., $200 \mathrm{eV}$ blackbody), the photoelectric effect dominates the total cross section. At the higher energies expected from an IFE target $(\sim 1-10 \mathrm{keV})$, the Compton cross section is comparable to the photoelectric effect. While an interaction via the photoelectric effect results in the absorption of the photon, Compton interactions merely scatter the incident photon and only a portion of its energy is absorbed. The current $\mathrm{x}$-ray deposition model assumes that all photons are destroyed upon interaction, and thus, Compton scattering is not correctly accounted for by the code.

Inaccurate modeling of Compton scattering can have either a conservative or nonconservative effect. If one is modeling $\mathrm{x}$-ray transport through a hard vacuum, then one would overestimate the $\mathrm{x}$-ray deposition in the solid material. If, however, one is modeling $\mathrm{x}$-ray transport through an intervening gas, then the absorption in the gas would be overestimated. This would result in less energy arriving at the solid material and an underestimation of the $\mathrm{x}$-ray deposition in that material.

Given the above, it is prudent to upgrade ABLATOR's x-ray transport/deposition package. Specifically, that part of the calculation will be performed using the TART Monte Carlo transport code [10]. TART will model the photon interactions in an exact manner, providing the $\mathrm{X}$-ray deposition in the various layers of the solid material. TART will account for an arbitrary pressure of fill gas between the target and solid material. The EPDL photon cross section library, which is used by TART, contains the same data that has been implemented within ABLATOR [11].

Additional modifications to ABLATOR will be needed as work progresses. Currently, ABLATOR considers only vaporization and melting/spall as material removal mechanisms. These mechanisms undoubtedly dominate material removal when one considers only single or a few shots. The rep-rated nature of IFE, however, is likely to emphasize other mechanisms that become apparent only when a large number of pulses are considered. As these "sub-threshold" mechanisms are discovered, ABLATOR will need to be updated to consider their effects:

Finally, ABLATOR's database may need to be extended to include additional materials. Currently, ABLATOR includes data for eight materials: aluminum, alumina, 


\section{Plan for PLEX X-Ray Ablation Experiments and Analysis}

graphite, fused silica, stainless steel 409 , silicon nitride, beryllium, and chromium. Materials such as tungsten, carbon fiber composites, and silicon carbide may be added to the database.

\section{Potential Collaborations}

There are a number of potential collaborations. UCSD is currently investigating the effects of surface contamination upon the laser-induced damage threshold of an optic. This work is of interest for three reasons: (1) the effects that surface contamination has upon the $x$-ray ablation threshold could be studied using the contamination methods developed by the UCSD team, and (2) the UCSD team has assembled a set of highquality instruments for the diagnosis of optical properties. These instruments, if made available to our team, could help us determine the deleterious effects of a given level of $\mathrm{X}$-ray damage, and (3) the UCSD team could be a valuable source of optical samples.

NIF, even in its early years of operation without ignition targets, will generate significant fluxes of soft $\mathrm{X}$-rays. These $\mathrm{X}$-rays will pose a hazard to the survivability of the target positioner, diagnostics, and other equipment present within the target chamber during a shot. X-ray ablation can also cause problems for the NIF optics if material ablated from in-chamber components deposits upon them. NIF interest in using the PLEX facility will be gauged, and the possibility of exposing NIF samples will be evaluated. If there is sufficient interest from NIF and it appears that NIF irradiations can be performed without impacting the completion of Laser-IFE exposures, then a collaborative agreement will be established.

The heavy-ion fusion (HIF) community is currently focused on the use of thick-liquid protection schemes in which liquids are placed within $\sim 1 \mathrm{~m}$ of the indirect-drive target. Given the higher fusion yields, increased x-ray output from indirect-drive targets, and the close proximity of the materials, $x$-ray fluences approaching $1000 \mathrm{~J} / \mathrm{cm}^{2}$ are expected. Clearly, PLEX cannot contribute to the study of $\mathrm{x}$-ray ablation from the thick-liquid pocket. PLEX may be able to contribute to other $X$-ray ablation issues of interest to HIF. First, thick-liquid protection schemes have line-of-sight from the target up the beamlines. Typically, these beamlines are shielded using swirling vortices of liquid. These liquids would be subject to ablation at X-ray fluences of 10 's of J/cm at energies of $100-1000$ $\mathrm{eV}$. Second, PLEX might contribute to studies of $\mathrm{x}$-ray ablation for power plant designs using thin-liquid protection schemes, where the first material is encountered at a distance of 3-6 m from the target. Such designs would be subject to $\mathrm{x}$-ray fluences of 25-100 $\mathrm{J} / \mathrm{cm}^{2}$. PLEX could not provide such high fluences, but it could contribute to studies of $\mathrm{X}$ ray ablation of HIF-relevant materials at energies of interest. Note that HIF designs do not necessarily need to avoid $x$-ray ablation; they need to accurately predict the quantity of ablated material and understand its evolution in time to ensure that the chamber is adequately cleared prior to the next shot. Again, if there is sufficient mutual interest and if the HIF exposures can be completed without negatively impacting the ability to complete Laser-IFE exposures, then an arrangement will be reached. 


\section{Plan for PLEX X-Ray Ablation Experiments and Analysis}

\section{Project Budget}

The project cost for PLEX is divided into recurring and non-recurring expenses. Procurement of the facility was detailed above and is summarized here in Table 2. Facility operation will require a number of personnel as well as samples and other equipment. Routine maintenance has been estimated.

The steady-state level of support for operations consists of an experimental scientist (Latkowski, principle investigator), computational analyst (Reyes), and mechanical engineering technician (Pletcher), each at a 50\% level of effort. An additional 20\% technician support is required for sample preparation and post-irradiation analysis. Safety and other facility support will require $10 \%$ of an FTE. Space charges are estimated at $\$ 25 \mathrm{~K} /$ year. Samples and other supplies at estimated at $\$ 30 \mathrm{~K} /$ year.

Personnel and maintenance costs for FY02 assume a delivery date of $2 / 1 / 2002$, and thus, 8 months of PLEX operation during FY02. Additional technician time (10\% FTE) is included for the 4 months prior to delivery for laboratory set-up. Additional scientist and analyst time (10\% FTE) is also included for these 4 months to allow for development of a more detailed experimental plan and completion of initial scoping calculations.

Maintenance activities include periodic replacement of the pinch components after $\sim 10^{6}$ shots and replacement of the six thyratrons after $\sim 10^{9}$ shots. Even for facility operation at $25 \%$ capacity for 40 hours per week for 4 years, there would be $<10^{8}$ pulses. Thus, thyratron replacement should be unnecessary during the program lifetime.

Table 2. Estimated cost for PLEX procurement and operation, $\mathrm{K} \$$.

\begin{tabular}{lcccc}
\hline Description & FY02 & FY03 & FY04 & FY05 \\
\hline $\begin{array}{l}\text { Procurement of PLEX, } \\
\text { chiller, and applicable taxes* }\end{array}$ & 369 & - & - & - \\
\hline Experimental scientist & 102 & 146 & 151 & 157 \\
\hline Computational analyst & 88 & 125 & 130 & 135 \\
\hline $\begin{array}{l}\text { Mechanical engineering } \\
\text { technician }\end{array}$ & 70 & 104 & 108 & 112 \\
\hline $\begin{array}{l}\text { Sample preparation and post- } \\
\text { irradiation analysis }\end{array}$ & 13 & 20 & 20 & 20 \\
\hline Safety/facility support & & & & \\
\hline Samples and supplies & 25 & 25 & 25 & 25 \\
\hline Space charges & 30 & 30 & 30 & 30 \\
\hline Maintenance & 25 & 25 & 25 & 25 \\
\hline Travel & 10 & 10 & 10 & 10 \\
\hline Total & 10 & 10 & 10 & 10 \\
\hline
\end{tabular}

*Note: There may be an additional procurement cost if progress on borrowing an x-ray spectrometer, CCD camera, etc. stalls. 


\section{Plan for PLEX X-Ray Ablation Experiments and Analysis}

\section{References}

[1] L. Snead, N. M. Ghoniem, and J. D. Sethian, "Integrated Plan for Materials R\&D in Laser Inertial Fusion Energy (IFE)," (Aug. 2001).

[2] S. E. Bodner, D. G. Colombant, A. J. Schmitt, and M. Klapisch, "High-Gain DirectDrive Target Design for Laser Fusion," Phys. Plasmas 7 (Jun. 2000) 2298-2301.

[3] L. John Perkins et al., "Output Spectra from Direct and Indirect Drive Targets for Inertial Fusion Energy", Presented at the ARIES Project Meeting, Princeton Plasma Physics Laboratory (Sep. 2000).

[4] A. T. Anderson, "X-Ray Ablation Measurements and Modeling for ICF Applications," Lawrence Livermore National Laboratory, UCRL-LR-125352 (Sep. 1996).

[5] A. T: Anderson, A. K. Burnham, M. T. Tobin, and P. F. Peterson, "Modeling and Experiments of X-Ray Ablation of National Ignition Facility First Wall Materials," Fusion Technol. 30 (Dec. 1996) 757-763.

[6] M. McGeoch, "Radio-Frequency, Pre-ionized Xenon Z-Pinch Source for Extreme Ultraviolet Lithography," Appl. Optics 37, 1651-1658 (March 1998).

[7] I. N. Sviatoslavsky et al., "A KrF Laser Driven Inertial Fusion Reactor: SOMBRERO," Fusion Technol. 31 (May 1992) 1470-1474.

[8] M. S. Tillack et al., "ARIES Inertial Fusion Chamber Assessment," Fusion Technol. 39 (Mar 2001) 343-349.

[9] R. W. Moir, "Final Optics Protection in Laser Inertial Fusion with Cryogenic Liquid Droplets," Lawrence Livermore National Laboratory, UCRL-ID-140559 (Aug. 2000).

[10] D. E. Cullen, "TART98: A Coupled Neutron-Photon 3-D, Combinatorial Geometry Time-Dependent, Monte Carlo Transport Code," Lawrence Livermore National Laboratory, UCRL-ID-126455, Rev. 2 (1998).

[11] D. E. Cullen, M. H. Chen, J. H. Hubbell, S. T. Perkins, E. F. Plechaty, J. A. Rathkopfand J. H. Scofield, "Tables and Graphs of Photon-Interaction Cross Sections from $10 \mathrm{eV}$ to $100 \mathrm{GeV}$ Dervied from the LLNL Evaluated Photon Data Library (EPDL)," Lawrence Livermore National Laboratory, UCRL-50400-Volume 6, Rev. 4 (1989). 